\title{
Investigating the relationship between the frequency of flooding over the central United States and large-scale climate
}

\author{
IMAN MALLAKPOUR AND GABRIELE VILLARINI
}

IIHR-Hydroscience \& Engineering, The University of Iowa, Iowa City, Iowa, USA

Manuscript submitted to

Advances in Water Resources

Corresponding author address:

Iman Mallakpour, IIHR-Hydroscience \& Engineering, The University of Iowa, 323-23 C.

Maxwell Stanley Hydraulics Laboratory, Iowa City, 52242, Iowa, USA. E-mail: iman-

mallakpour@uiowa.edu. Tel.: (520) 548-3311 


\begin{abstract}
The aim of this study is to examine whether the climatic driving forces can describe the observed variability in the frequency of flooding over the central United States. Results are based on daily streamflow records from 774 U.S. Geological Survey (USGS) stations with at least 50 years of data and ending no earlier than 2011. Five climate indices related to both the Atlantic and Pacific Oceans are used in this study: the North Atlantic Oscillation (NAO), the Southern Oscillation Index (SOI), the Pacific Decadal Oscillation (PDO), the Atlantic Multidecadal Oscillation (AMO), and the Pacific-North American pattern (PNA). A peak-over-threshold approach is used to identify flood peaks, and the relationship between the frequency of flood events and climate indices is investigated using Poisson regression.
\end{abstract}

The results of this work indicate that climate variability can play a significant role in explaining the variations in the frequency of flooding over the central United States. Different climate modes are related to the frequency of flood events over different parts of the domain and for different seasons, with PNA playing an overall dominant role. Analyses related to flood events are extended to examine climate controls on heavy precipitation over the same area. We find that the variability of the Atlantic and Pacific Oceans can influence the frequency of heavy precipitation days in a manner similar to what was found for flooding. Therefore, these results suggest that the recent observed variability in the frequency of flood events and heavy precipitation over the central United States can be largely attributed to the variability in the climate system. 


\section{Introduction}

The central United States is a region of the country plagued by frequent catastrophic flooding (e.g., flood events of 1993, 2008, 2011, 2013, and 2014), with large economic and social repercussions (e.g., fatalities, agricultural losses, flood losses, water quality issues). For example, \$34 billion in economic damage and 48 fatalities were caused by the 1993 Midwest flooding (NCDC, 2015). During the June 2008 Midwest flood, 24 people lost their lives, 140 were injured (Dirmeyer and Kinter, 2009), and the total economic damages were in excess of \$11 billion (NCDC, 2015). The Mississippi and Missouri flooding of April-June 2011 caused economic losses on the order of $\$ 5$ billion and 12 fatalities (NCDC, 2015). Because of all these devastating flooding events over the central United States, there has been a large interest in analyzing the observed streamflow records to detect variability in flood magnitude and/or frequency (e.g., Lins and Slack, 1999, Schilling and Libra, 2003, Lins and Cohn, 2011, Villarini et al., 2011b, Hirsch and Ryberg 2012, Slater et al., 2015, Mallakpour and Villarini, 2015).

Recently, Mallakpour and Villarini (2015) showed that over the past 50+ years, it is not an increase in the magnitude but in the frequency of flood events that is detectable from the observational records over the central United States. They also found that these changes can be largely related to changes in the frequency of heavy precipitation events. The next question to address is then: why has the frequency of precipitation, and consequently flooding, been changing over the second half of the $20^{\text {th }}$ century and into the first decade of the $21^{\text {st }}$ century? Our hypothesis is that the variability in the climate system related to both the Atlantic and Pacific Oceans can influence the frequency of flooding and heavy precipitation over the central United States. 
There are different meteorological, hydrological and climatological mechanisms that bring moisture that can produce flooding (i.e., tropical cyclone, convection, thunderstorm, frontal passages, sea surface temperature (SST) anomalies, and jet streams) (Hirschboeck, 1988). Hirschboeck (1988) classified these mechanisms based on the difference in time and space scales as "proximate" (direct and immediate climatic causes) and "ultimate" (climatic mechanisms operating at larger and longer scales) factors. For example, a series of warm season convective systems over a period of two weeks were identified as the "proximate" cause of the 2008 Midwest flood (e.g., Coleman and Budikova, 2010, Budikova et al., 2010, Smith et al., 2013). However, the excess moisture for these series of storms was brought by the "ultimate" mechanisms such as the Great Plains Low Level Jet (GPLLJ) which interacted with a strong North American jet (e.g., Coleman and Budikova, 2010, Budikova et al., 2010, Smith et al., 2013). Higgins et al. (1997) showed the role played by the GPLLJ in transporting moisture leading to precipitation over the central United States (see also Nayak et al. (2016)). SST anomalies in the North Atlantic, SST anomalies in the Pacific, and GPLLJ are among the factors that can cause extreme flooding over the central United States (e.g., Lavers and Villarini, 2013, Patricola et al., 2015). Coleman and Budikova (2010) examined the climatological causes of the 2008 Midwest flood, and indicated that a mixture of different large-scale oceanic-atmospheric circulation brought moisture that produced the 2008 flooding.

The ocean and atmosphere are dynamic systems; coupled together, they structure a complex, ever-changing system that governs our planet's climate (e.g., Hidore et al., 2009). Coupled oceanic-atmospheric variations can occur at different time scales, from intra-annual to interannual, to decadal and inter-decadal (e.g., Tootle et al., 2005). Climate variability at these timescales is known as low frequency, as opposed to synoptic to seasonal climate variability 
which is commonly referred to as high frequency. Low frequency variability in the coupled oceanic-atmospheric system causes variability in the atmospheric flow (e.g., Sheridan, 2003), which is one of the main reasons for the variability of climatic patterns. Climate variability can affect and control the jet streams and storm tracks that are controlling extreme hydrological events (e.g., flood, heavy precipitation, drought; e.g., Andersen and Shepherd, 2013).

In this study, we examine the relationship between the frequency of flood events and largescale climate indices over the central United States using five indices reflecting the influence of the Atlantic and Pacific Oceans. These climate indices are the North Atlantic Oscillation (NAO; e.g., Hurrell, 1995), the Southern Oscillation Index (SOI; e.g., Ropelewski and Jones, 1987), the Pacific Decadal Oscillation (PDO; e.g., Mantua et al. 1997), the Atlantic Multidecadal Oscillation (AMO; e.g., Enfield et al., 2001), and the Pacific-North American pattern (PNA; e.g., Leathers et al., 1991). Each of the above-mentioned climate indices has the potential to describe certain spatial and temporal aspects of the climate variability.

There is a growing number of studies examining the relationship between hydrological processes and climate variability. These studies show that low frequency climate variability to some extent can control precipitation (e.g., Leathers et al., 1991, Enfield et al., 2001, Durkee et al., 2008), groundwater level (e.g., Kuss and Gurdak, 2014), streamflow (e.g., Enfield et al., 2001, Tootle et al., 2005, Tootle and Piechota, 2006, Sagarika et al., 2015), and drought (e.g., McCabe et al., 2004). Contrasting results have been found regarding the relationship between streamflow and climate variability in the continental United States. McCabe and Wolock (2014) investigated spatial and temporal changes in the streamflow characteristics throughout the United States. In general, they found weak correlations between mean annual streamflow and climate indices they examined (i.e., El Niño-Southern Oscillation (ENSO), PDO, AMO, PNA and 
NAO). The authors indicated that temporal changes in mean annual streamflow were not predictable by climate indices. However, Tootle et al. (2005) evaluated the streamflow responses to four climate indices (i.e., PDO, NAO, AMO, and ENSO) and found that they can influence the streamflow variability over the continental United States. Indeed, they concluded that potentially valuable information for streamflow forecasters and water managers can be provided by investigating the relationship between climate indices and streamflow conditions. While in the past the relationship between discharge and climate was explored, the focus was on average annual streamflow, annual maxima or volume, rather than on the frequency of flood events as in this study.

The goal of our study is to examine whether there is any relationship between climate variability and the frequency of flooding over the central United States. If we can identify such a relationship as hypothesized above, then it would have the potential to help understand and predict future flood conditions. In other words, understanding the relationship between climate variability and flooding could have the potential to improve future water management and our preparation against these catastrophic events. Inter-annual to decadal climate predictions have been gaining attention for short-term decision making, flood defense, and water planning (e.g., Wang et al., 2015). However, we have to keep in mind that the reliability of flood predictions is heavily dependent on the accuracy of the predictions of climate indices. A number of studies have shown that large-scale climate indices can be used to forecast streamflow (e.g., Sankarasubramanian and Lall, 2003, kwon et al., 2008, Hamlet and Lettenmaier, 1999, Kalra and Ahmad, 2009, Risko and Martinez, 2014). For instance, Kwon et al. (2008) used a hierarchical Bayesian modeling framework to investigate the seasonal forecasting of flooding events in Montana using climate indices such as ENSO and PDO. However, one of the challenges in using 
large-scale climate indices to forecast streamflow is choosing "the optimal” ones (e.g., Risko and Martinez, 2014). Kalra and Ahmad (2009) used ENSO, NAO, PDO and AMO for 3-year lead time streamflow forecasting over the Upper Colorado River Basin; they indicated that ENSO and NAO were the best set of climate indices for predicting annual streamflow over that region. Here we want to find the "optimal" set of climate indices that can describe the relationship between climate and the seasonal frequency of flood events over the central United States.

The rest of this paper is organized as follows. In the next section, we describe the observational data (streamflow, precipitation) and the climate indices. In Section 3 we briefly describe the statistical methods we use to relate the frequency of flood and precipitation events to the different climate indices, with the corresponding results presented in Section 4. We summarize the major findings of this study and conclude this paper in Section 5.

\section{Data}

This study focuses on the central United States, which includes North Dakota, South Dakota, Nebraska, Kansas, Missouri, Iowa, Minnesota, Wisconsin, Illinois, West Virginia, Kentucky, Ohio, Indiana, and Michigan (Figure 1a). We use daily streamflow records from 774 U.S. Geological Survey (USGS) stream gauges that have at least 50 years of data that end no earlier than 2011, and with a gap no larger than two years (Figure 1, panels b and c). A year counts as complete when streamflow data are available for at least 330 days (less than $10 \%$ missing days). Even though we focus on stations with at least 50 years of data, most of the stations have 60 to 80 years of data, providing a comprehensive view of discharge over the second half of the $20^{\text {th }}$ century and into the first decade of the $21^{\text {st }}$ century. Analyses are done on 
four seasonal blocks (spring, summer, fall, and winter). Precipitation analyses are based on unified Gauge-Based daily observation data available from the National Oceanic and Atmospheric Administration (NOAA) Climate Prediction Center (CPC) from 1948 to 2012 (Higgins et al., 2000). This daily product has a grid resolution of 0.25-degree.

The streamflow and precipitation data are complemented by five climate indices reflecting the Atlantic and Pacific Oceans. The NAO index is one of the leading modes of inter-annual to decadal timescale variability in the oceanic-atmospheric system and describes the large-scale change in the atmospheric mass over the North Atlantic Ocean (Hurrell, 1995). The negative (positive) NAO values represent weaker (stronger) than average pressure centers over the subtropical high and subpolar low regions, which result in weaker (stronger) westerly winds (e.g., Hurrell, 1995, Sheridan, 2003, Kuss and Gurdak, 2014). Traditionally, NAO is calculated using the normalized sea level pressure anomaly difference between the Azores and Iceland (e.g., Hurrell, 1995, Stenseth et al., 2003, Portis et al., 2001). However, the downside of using the traditional NAO is that the pressure differences between the subtropical high and subpolar low regions are much more pronounced during the winter season. Because here we do not limit our analyses to the winter season, we use the "mobile" NAO index based on Portis et al. (2001), which is a seasonally and geographically changing NAO index. Portis et al. (2001) determined this mobile NAO index by subtracting normalized SLP anomalies at the locations of North Atlantic Ocean where SLP between subtropical and subpolar showed the maximum negative correlation for each month. We have computed the mobile NAO index data for the 1948-2012 period based on the monthly mean SLP reanalysis dataset with a grid resolution of 2.5-degree that was available from National Centers for Environmental Prediction-National Center for Atmospheric Research (NCEP-NCAR) reanalysis dataset. 
The ENSO index used in this study is based on the SOI index which can be determined by using the sea level pressure differences between Tahiti and Darwin (e.g., NOAA, 2015, Arghaninejad and Median, 2013, Ropelewski and Jones, 1987, Trenberth, 1984). The negative (positive) values of the SOI represent El Niño (La Niña) episodes in the Pacific Ocean (NOAA, 2015). The SOI index was obtained from the NOAA CPC (http://www.cpc.ncep.noaa.gov/data/indices/soi) for the period of 1951-2012.

The PDO index is the mode of climate variability related to decadal to inter-decadal variability in the atmospheric system. This index is defined based on the monthly SST over the Pacific Ocean, north of $20^{\circ} \mathrm{N}$ after the global mean sea surface temperature has been removed (e.g., Mantua et al. 1997, Mantua and Hare, 2002). This index consists of positive (warm) and negative (cold) phases where each phase can last from 20 to 30 years (e.g., Tootle et al., 2005). Hamlet and Lettenmaier (1999) indicated that the effects of positive (negative) phase of the PDO are similar to the impacts of El Niño (La Niña) episodes. The PDO index was downloaded from the CPC website (http://www.esrl.noaa.gov/psd/data/correlation/pdo.data) for the period of 19482012.

The AMO index is a climate variability mode identified as a natural leading pattern of the low-frequency SST variability over the North Atlantic Ocean from $0^{\circ}$ to $70^{\circ} \mathrm{N}$ (e.g., Enfield et al., 2001, Tootle et al., 2005). Enfield et al. (2001) indicated that this mode can control the strength of the thermohaline circulation over the Atlantic Ocean and has an oscillation on the order of 60-80 years. This index also consists of two phases, positive and negative. The AMO index was downloaded from the CPC website (http://www.esrl.noaa.gov/psd/data/correlation/amon.us.data) for the period of 1948 to 2012. 
The PNA index can describe the variation of the jet streams in the Northern Hemisphere's mid-latitudes, particularly over North America (e.g., Leathers et al., 1991). Leathers et al. (1991) indicated that the PNA index has a strong connection with the surface weather over the United States. The PNA index is calculated by using the mid-latitudes 500-mb geopotential height anomalies over the Pacific Ocean and North America. This index is characterized by a positive phase that reflects above normal geopotential heights near Hawaii and near Alberta and below normal geopotential heights located in the Aleutian low and Florida; the negative phase, on the other hand, shows below normal geopotential heights over the western United States and above normal geopotential heights over the eastern United States, leading to more zonal flow over the United States (e.g., Sheridan, 2003). The PNA index was obtained from the CPC website (http://www.cpc.ncep.noaa.gov/data/teledoc/pna.shtml) for the period 1950-2012.

All the climate indices are available at the monthly scale. In performing our seasonal analyses, we average the monthly values to the season of interest (Winter: December-JanuaryFebruary; Spring: March-April-May; Summer: June-July-August; Fall: September-OctoberNovember).

To connect the insights from the statistical analyses to the processes, we also compute the integrated vapor transport (IVT) and use the 500-mb geopotential height (GPH). IVT ( $\mathrm{kg} \mathrm{m}^{-1}$ $\mathrm{s}^{-1}$ ) is a quantity that describes the total amount of transported water vapor to a location, and is calculated by integrating specific humidity, zonal and meridional winds across different atmospheric levels (e.g., from the surface to $300 \mathrm{hPa}$; Neiman et al., 2008, Lavers and Villarini, 2013, Nayak et al., 2016 ). IVT used in this study is based on NCEP-NCAR reanalysis dataset for the 1948-2012 period, with a grid resolution of 2.5-degree, which also represents the source of information for the 500-mb GPH. 


\section{Methods}

To calculate the frequency of flood events over the central United States, the peaks-overthreshold (POT) method is used. Unlike the annual maximum flow (AMF) approach that includes only one event per year, a threshold can be set to capture a wider range of events (e.g., Lang et al., 1999). In this study, the threshold is selected to give on average two flood events per year, with no more than one event in a 2-week time window (to not allow for counting the same events multiple times). For detecting the changes in the frequency of heavy precipitation, we use the POT method as well. The threshold is selected based on the $95^{\text {th }}$ percentile of the precipitation distribution at each pixel (e.g., Villarini et al., 2013a). After setting the thresholds for streamflow and precipitation, we count the number of events that exceeded the threshold in every season for each grid cell or stream gage location.

We use Poisson regression to investigate the relationship between climate indices (predictors) and the number of flood and heavy precipitation events (predictands). Poisson regression represents the proper statistical method because the response variable (i.e., number of flood events, number of heavy precipitation events) is in the form of count data and has a discrete nature. The key assumptions to use the Poisson regression are that the response variables are independent and following a Poisson distribution (e.g., Dobson 2001, Fox, 2015). The Poisson probability distribution can be written as follows:

$$
P\left(N_{i j}=k \mid \lambda_{i j}\right)=\frac{e^{-\lambda_{i j} \cdot \lambda_{i j}^{k}}}{k !} \quad(k=0,1,2, \ldots)
$$

where $N_{\mathrm{ij}}$ represents the number of events in a particular season $j$ of year $i$, and $\lambda_{\mathrm{ij}}$ is the rate of occurrence parameter which is a nonnegative random variable. 
For each of the USGS stations or precipitation pixels, we evaluate the presence of a statistically significant relationship between the frequency of flood events and climate indices by fitting a Poisson regression model. The rate of occurrence parameter $\lambda$ depends linearly on the climate indices (by means of a logarithmic link).

$$
\lambda_{i j}=\exp \left(\beta_{0, j}+\beta_{1, j} \cdot C_{i j}\right)
$$

where $C_{\mathrm{ij}}$ is value of climate index in the $\mathrm{j}^{\text {th }}$ season of the $\mathrm{i}^{\text {th }}$ year, and $\beta_{0}$ and $\beta_{1}$ are the coefficients to estimate via maximum likelihood.

Here we focus on statistical relationships that are significant at the $5 \%$ and $10 \%$ levels; this means that we will focus on coefficients $\beta_{1}$ that are different from zero at the $5 \%$ and $10 \%$ levels. A positive (negative) value of $\beta_{1}$ indicates that, on average, we would expect an increase (decrease) in the number of flood or precipitation events for an increase in the value of the climate index.

We use the multiple Poisson regression model to find the optimal climate index or set of climate indices that can describe the temporal variability in the seasonal frequency of flood events over the central United States. For each of the USGS stations or precipitation pixels, we consider all the models that represent all the possible combinations of predictors (from one to five climate indices), for a total of 31 different models. We select the best model based on two criteria: first, we select a subset of models for which all the estimated coefficients for each of the climate indices are different from zero at the $10 \%$ significant level. Then we select as the final model out of this subset the one with the smallest value of the Akaike information criterion (AIC; Akaike, 1974). 
As described in Section 2, the period of availability for each of the climate indices is slightly different. In performing the multiple Poisson regression, we focus on the common period from 1951 to 2011. All the calculations are performed in R (R Development Core Team, 2012).

\section{Results}

\subsection{Relationship between each climate index and the frequency of flooding and heavy precipitation events}

Figure 2 (panels a-d) displays the statistically significant results of the relationship between flood frequency and PDO over the central United States. Overall, 20\% (27\%) of the stations present statistically significant relationships at the 5\% (10\%) significant level in winter and spring, while $20 \%$ (30\%) occur in the summer, and 11\% (19\%) in the fall. More important than the raw numbers describing the percent of stations showing statistically significant results is the geographical pattern of the relationship between PDO and frequency of flooding. During spring, a broad region from southern Minnesota to Kansas shows a positive relationship between PDO and the frequency of flooding, while there is a negative tendency in northern Minnesota, Wisconsin and Michigan. During the summer, PDO and flood events are generally positively related in a swath from Ohio and Indiana, across Illinois and Iowa and into southern Minnesota. During the fall, the clearest clusters are in Wisconsin, southern Illinois and Missouri. Finally, in the winter there is a large area encompassing West Virginia, Ohio, Kentucky and eastern Illinois with a negative relationship between PDO and the number of flood events. Figure 2 (panels e-h) presents the results of the relationship between heavy precipitation frequency and PDO. For all the seasons, there are striking similarities (both in terms of geographic location and sign) with what we found for flooding (Figure 2, panels a-d). The fact that we find significant relationships between PDO and flooding is consistent with previous studies (e.g., Nigam et al., 1999, Tootle et 
al., 2005) where they observed a statistically significant link between PDO and the annual streamflow variability for the upper to middle Mississippi River basin.

Figure 3 (panels a-d) presents the results for the relationship between flood frequency and NAO. Overall, 15\% (25\%) of the stations present statistically significant relationships at the $5 \%$ (10\%) significant level in the spring, 33\% (40\%) occur in the summer, $8 \%(15 \%)$ in the fall, and $6 \%(10 \%)$ in the winter. During spring, the frequency of flooding is negatively related to the NAO index mostly west of Wisconsin and Illinois; on the other hand, there is a positive relationship in Michigan and Indiana. During the summer, about 31\% (38\%) of the stations exhibit a statistically significant negative relationship at the 5\% (10\%) significant level with NAO over a broad region from the Dakotas to Indiana and Ohio. On the other hand, the link between NAO and flood frequency is weak for fall and winter. Figure 3 (panels e-h) shows the results of the relationship between heavy precipitation frequency and NAO. Overall, the results are similar to what discussed for flooding. These results are in line with Tootle et al. (2005), where they observed a significant negative relationship between NAO and average annual streamflow variability over the upper to the middle Mississippi River Basin. Also, studies have found a strong connection between the strength of the GPLLJ and the negative phase of the NAO (e.g., Weaver and Nigam, 2008, Coleman and Budikova, 2010). Weaver and Nigam (2008) tied the negative NAO with heavy precipitation over the U.S. Midwest. Coleman and Budikova (2010) showed that NAO was in a strong negative phase during the summer flood of 2008 over the U.S. Midwest.

Figure 4 (panels a-d) presents the results of the relationship between flood frequency and AMO. Here $16 \%$ (23\%) of the stations show a statistically significant relationship at the $5 \%$ (10\%) significant level in the spring, $15 \%$ (24\%) in the summer, $13 \%$ (21\%) in the fall, and $8 \%$ 
(15\%) in the winter. During spring, two distinct clusters of stations were identified: the eastern portion of the study region shows a positive relationship while the western region displays a negative relationship. During the summer, about 98\% (102 stations) of all the stations that are revealing a statistically significant relationship at the 5\% significant level are showing a positive relationship. These stations are located in the areas from the Dakotas into Illinois, Indiana, and Ohio; overall, this pattern resemble what discussed for the NAO (Figure 3b), but weaker. During fall, the central part of the study area displays a cluster of stations with a negative relationship. During winter, the signal of the relationship between AMO and flood frequency is weak, with a limited spatially coherent area in the southern part of the study area. Overall, the results for the AMO are weaker than what observed for the NAO and PDO. Figure 4 (panels e-h) shows the results of the relationship between heavy precipitation frequency and AMO, with findings and conclusions similar to the results for flooding. Overall, our findings are consistent with published results, Enfield et al. (2001) examined the seasonality of the correlation between precipitation and AMO, and found that the summer season showed the highest significant correlations. Tootle et al. (2005) found areas with a statistically significant positive link between AMO and streamflow variability for the upper and middle Mississippi River basin. Also, McCabe and Wolock (2014) found weak and mostly negative correlations between AMO and annual streamflow over the central Unites States.

Figure 5 (panels a-d) displays the results of the relationship between flood frequency and SOI. Overall, $14 \%$ (22\%) of the stations exhibit a statistically significant relationship at the $5 \%$ (10\%) significant level in the spring, $11 \%(19 \%)$ in summer, $11 \%(18 \%)$ in the fall, and $7 \%$ (13\%) in the winter. In general the relationship between SOI and flood frequency is weak in all the seasons. However, the most coherent geographical relationship can be found during spring, 
where we can identify three clusters of stations: the central and southwestern portion of the study region with a negative relationship, the eastern region with a positive relationship and the northwestern part of the study region with a positive relationship. Tootle et al. (2005) found that the strongest link between streamflow variability and ENSO can be observed in Florida, Arizona, Southern California and the Pacific Northwest, not over the central United States. Figure 5 (panels e-h) shows that the results of the relationship between heavy precipitation frequency and SOI are similar to what discussed for flooding. Villarini et al. (2011a) examined the relationship between annual maximum rainfall and SOI over the U.S. Midwest, where they could not found noticeable statistically significant spatial patterns between extreme rainfall and SOI in this region.

Finally, Figure 6 (panels a-d) displays the results of the relationship between flood frequency and PNA. Statistically significant results were found in different locations for each season. Overall, $20 \%$ (27\%) of the stations present a statistically significant relationship at the $5 \%$ (10\%) significant level in the spring, 26\% (33\%) in the summer, 31\% (42\%) in the fall, and 28\% (36\%) in the winter. Among all the climate indices considered in this study, the relationship between PNA and flood frequency is the most dominant one. During spring, the southwestern portion of the study region shows a strong positive relationship between flood frequency and PNA. During the summer, there is an extended region that ranges from North Dakota to Iowa and Missouri, and east into Wisconsin, Illinois, Indiana, and Ohio showing a negative relationship. For the fall, there is a pronounced negative relationship over the study area, especially strong over the south-west / north-east swath from Kansas to Michigan and Ohio. For winter, a strong negative relationship between PNA and flood frequency can be observed over the southeastern part of the study area, from southern Missouri into Michigan, Ohio and West 
Virginia. Figure 6 (panels e-h) shows the results for the relationship between the frequency of heavy precipitation and PNA. Overall the conclusions we can draw about the influence of PNA on the frequency of heavy precipitation are markedly similar to what mentioned for the frequency of flooding. This pattern is similar to what was found by McCabe and Wolock (2014) regarding the relationship between PNA and average annual streamflow over the northern United States where they found a negative correlation between average streamflow and PNA over the eastern part of our study region. Moreover, our results are consistent with Ning and Bradley (2014), who found a negative correlation between the number of days with precipitation larger than $10 \mathrm{~mm}$ and PNA during the winter season. Also, Coleman and Budikova (2010) indicated that the negative phase of the PNA during winter is related to more precipitation and higher average streamflow over the Ohio River Valley region.

\subsection{Identification of the relationship between the frequency of flooding and heavy precipitation and climate indices using multiple Poisson regression}

In Section 4.1 we examined the relationship between the frequency of heavy precipitation and flooding and each of the climate indices. While several interesting patterns were identified, there were also areas that seemed to be controlled by two or more climate indices (e.g., PDO and PNA in the winter). Here we perform multiple Poisson regression to identify the dominant climate indices for each season.

Table 1 and Figure 7 summarize the results of the multiple Poisson regression. Overall, the regression models that contain PNA as one of the covariates are the ones that can better describe the variability in the frequency of flooding in all four seasons. During spring, depending on the location, the variability in the frequency of flooding can be driven by at least one of the five climate indices. The relationship between flood frequency and climate indices in the summer can 
be generally defined by the models that contain at least one or a subset of the NAO, PDO, and PNA as covariate. During fall, there is a clear negative relationship between PNA and the frequency of flooding, while the PDO is positively related. For winter, there is a pronounced negative relationship over the southern part of the central United States between the frequency of flooding and PNA. In Section 4.1 we have investigated the relationship between each of the climate indices and the frequency of flooding: we found that both PNA (Figure 2d) and PDO (Figure 6d) were significantly related to the frequency of flooding over the region from Kansas to Michigan and West Virginia. The results in Figure 7, however, point to PNA as the major driver over the majority of the stations within this area, with PDO no longer identified as a significant predictor.

We have also extended these analyses to the frequency of heavy precipitation events (Figure 8). Overall, the findings for streamflow can be transferred to heavy precipitation, with PNA being the dominant climate mode across much of our domain and for all the seasons. The main difference is for the fall season, in which the strongest relationship between flooding and PNA is in the southeastern part of the domain, while the frequency of heavy rainfall is related to PNA in the northwestern part of the study area. A possible explanation can be found in the seasonality of flooding over this area, with the fall season contributing very little to the overall number of heavy rainfall and flood events (e.g., Mallakpour and Villarini 2015, Villarini 2016).

To a large extent, for all the seasons and across much of our study area, we found that the relationship between heavy precipitation and flooding with PNA is the dominant one. Mostly, this relationship has a negative sign, indicating that, on average, we would expect an increase in the number of flood or heavy precipitation events during the negative phase of PNA. To investigate the physical mechanisms responsible for these findings, we examine the seasonal 
anomalies in IVT, 500-mb GPH, and in the frequency of heavy precipitation and flood events during the negative phase of PNA (Figure 9). The results show that there is an anomalously high transport over the central and south-eastern United States during the negative phase of PNA (Figure 9, left column; see also Leathers et al. (1991) and Harding and Snyder (2015)). This is particularly true in the spring and winter, even though weaker but positive IVT anomalies are still present over our study region. These patterns in moisture transport are also tied to the anomalies in 500-mb GPH (contour lines in Figure 9), with high pressure area (ridge) over the southeastern United States and low pressure region (trough) over much of the western United States. The same regions with strong positive IVT anomalies are associated with an aboveaverage frequency of heavy rainfall and flooding (Figure 9, middle and right panels). Therefore, these results indicate that during the negative phase of PNA, there is large moisture transport leading to an increasing frequency of heavy rainfall and flooding.

The fact that we see similar spatial and temporal patterns in terms of the relationship between climate indices and heavy precipitation and flooding allows us to infer that the variability in the frequency of flood events across the central United States are tied to variability in the climate system through their effects on heavy precipitation.

\section{Conclusions}

In this study we have examined the relationship between climate variability and the frequency of flood and heavy precipitation over the central United States (the study area includes North Dakota, South Dakota, Nebraska, Kansas, Missouri, Iowa, Minnesota, Wisconsin, Illinois, West Virginia, Kentucky, Ohio, Indiana, and Michigan) during the second half of the $20^{\text {th }}$ and the first decade of the $21^{\text {st }}$ centuries. We have analyzed the seasonal daily streamflow records for 774 USGS streamflow gages with at least 50 years of data. Because of the discrete nature of 
these data, we used Poisson regression to describe the relationship between climate indices and the response variable (frequency of flood or frequency of heavy precipitation). Five climate indices (NAO, SOI, PDO, AMO, and PNA) were used to examine these relationships.

Our results indicate that the climate variability of both the Atlantic and Pacific Oceans can affect the frequency of flood events over the central United State, with each of the climate indices that can describe certain spatial and temporal features of the relationship between climate variability and frequency of flooding. Among all the climate indices, the relationship between PNA and flooding was overall the most dominant one. The sign of the relationship between PNA and flood frequency was mostly negative, indicating that a more positive (negative) value of PNA, would result in a decrease (increase) in the frequency of flooding. The remaining four climate indices, on the other hand, showed a weaker and less spatially coherent signal.

In addition to analyzing the relationship between the frequency of flooding and climate indices, we also examined the relationship between climate indices and the frequency of heavy precipitation events. Our results indicate that the variability of the Atlantic Ocean and Pacific Ocean can influence the heavy precipitation frequency over the central United States in a manner very similar to what we found for flooding. We have found that PNA was the dominant climate mode, and the sign of the relationship between PNA and heavy precipitation frequency was largely negative. We found that these results can be explained in terms of above average moisture transport over our area, leading to an increased frequency of heavy rainfall and flood events. These results are consistent with Harding and Snyder (2015), who showed that during the negative phase of PNA, there is a higher amount of moisture transported over the central United States through the GPLLJ. Thus, the variation in the climate system is affecting the transport and availability of moisture. In general, when there is excess moisture in the system, that excess 
moisture can cause heavy precipitation which then can lead to flooding. Thus, we can view the issue of changes in the frequency of flood events as a hierarchy of problems. In fact, flood frequency over the central United States has been changing over the past 50+ years (Mallakpour and Villarini, 2015). These changes in the frequency of flooding are mostly driven by changes in heavy rainfall (Mallakpour and Villarini, 2015). Finally, the changes in heavy rainfall and flooding are largely driven by climate variability related to the influence of the Atlantic and Pacific Oceans.

The results of this study can provide the foundation for a number of additional lines of research. For instance, the insight gained from this work could be used to improve seasonal prediction systems, with the improved understanding of the relationship between climate variability and flooding that can provide basic information to improve future water management. In particular, by skillfully forecasting the PNA values over the season of interest we would be able to have information related to the number of flood events we could expect at a given location. Another future direction we are currently exploring is the extension of these results to the sub-seasonal scale. While the focus here has been on the total number of events in a given season, we do not have information related to how these events manifest themselves during a season. This can be accomplished using Cox processes to describe the temporal clustering of flood events (e.g., Smith and Karr, 1986, Villarini et al., 2013b). These and other related followup studies are currently underway. 


\section{Acknowledgments}

The authors acknowledge financial support by the USACE Institute for Water Resources, by the National Science Foundation under CAREER Grant AGS-1349827, by IIHR-Hydroscience \& Engineering and the Iowa Flood Center. This material is also based upon work supported by the Broad Agency Announcement (BAA) Program and the Engineer Research and Development Center (ERDC)-Cold Regions Research and Engineering Laboratory (CRREL) under Contract No. W913E5-16-C-0002. We thank Dr. Portis for providing the monthly nodes to compute the mobile NAO index, and two anonymous reviewers for comments and suggestions. 


\section{References}

Akaike, H. (1974). A new look at the statistical model identification. IEEE Trans. Autom. Control, 19, 716-723.

Andersen, T. K., and Shepherd, M. J. (2013). Floods in a changing climate. Geography Compass, 7(2), 95-115.

Araghinejad S. and Meidani, E. (2013). A Review of Climate Signals as Predictors of LongTerm Hydro- Climatic Variability, Climate Variability - Regional and Thematic Patterns, Dr. Aondover Tarhule (Ed.), ISBN: 978-953-51-1187-0, In Tech, DOI: 10.5772/56790.

Budikova, D., Coleman, J. S. M., Strope, S. A., and Austin, A. (2010). Hydroclimatology of the 2008 Midwest floods. Water Resources Research, 46(12).

Coleman, J. S., and Budikova, D. (2010). Atmospheric aspects of the 2008 Midwest floods: a repeat of 1993?. International Journal of Climatology, 30(11), 1645-1667.

Dirmeyer, P. A., and Kinter, J. L. (2009). The "Maya Express”: Floods in the US Midwest. Eos, Transactions American Geophysical Union, 90(12), 101-102.

Dobson, A.J. (2001), An Introduction to Generalized Linear Models (2nd ed.), CRC Press.

Durkee, J. D., Frye, J. D., Fuhrmann, C. M., Lacke, M. C., Jeong, H. G., and Mote, T. L. (2008). Effects of the North Atlantic Oscillation on precipitation-type frequency and distribution in the eastern United States. Theoretical and Applied Climatology, 94(1-2), 51-65.

Enfield, D. B., Mestas-Nuñez, A. M., and Trimble, P. J. (2001). The Atlantic multidecadal oscillation and its relation to rainfall and river flows in the continental US. Geophysical Research Letters, 28(10), 2077-2080.

Fox, J. (2015). Applied regression analysis and generalized linear models. Sage Publications.

Harding, K. J., and Snyder, P. K. (2015). The Relationship between the Pacific-North American Teleconnection Pattern, the Great Plains Low-Level Jet, and North Central US Heavy Rainfall Events. Journal of Climate, 28(17), 6729-6742.

Hamlet, A. F., and Lettenmaier, D. P. (1999). Columbia River streamflow forecasting based on ENSO and PDO climate signals. Journal of water resources planning and management, 125(6), 333-341.

Hidore, J. J., Oliver, J. E., Snow, M., and Snow, R. (2009). Climatology: An Atmospheric Science. Prentice Hall; 3 edition.

Higgins, R.W., Shi, W., Yarosh, E. and Joyce R. (2000). Improved United States precipitation quality control system and analysis, NCEP/Climate Prediction Center Atlas 7, 40 pp. 
Higgins, R. W., Yao, Y., Yarosh, E. S., Janowiak, J. E., and Mo, K. C. (1997). Influence of the Great Plains low-level jet on summertime precipitation and moisture transport over the central United States. Journal of Climate, 10(3), 481-507.

Hirsch, R.M., Ryberg K.R. (2012), Has the magnitude of floods across the USA changed with global $\mathrm{CO}_{2}$ levels? 57(1), 1-9.

Hirschboeck, K.K. (1988). Flood hydroclimatology, in Baker, V.R., Kochel, R.C. and Patton, P.C., eds., Flood Geomorphology, John Wiley \& Sons, 27-49.

Hurrell, J. W. (1995). Decadal trends in the North Atlantic Oscillation: regional temperatures and precipitation. Science, 269(5224), 676-679.

Kalra, A., and Ahmad, S. (2009). Using oceanic-atmospheric oscillations for long lead time streamflow forecasting. Water Resources Research, 45(3).

Kuss, A. J. M., and Gurdak, J. J. (2014). Groundwater level response in US principal aquifers to ENSO, NAO, PDO, and AMO. Journal of Hydrology, 519, 1939-1952. doi:10.1016/j.jhydrol.2014.09.069.

Kwon, H. H., Brown, C., and Lall, U. (2008). Climate informed flood frequency analysis and prediction in Montana using hierarchical Bayesian modeling. Geophysical Research Letters, 35(5).

Lang, M., Ouarda, T. B. M. J., and Bobée, B. (1999). Towards operational guidelines for overthreshold modeling. Journal of hydrology, 225(3), 103-117.

Lavers, D. A., and Villarini, G. (2013). Atmospheric rivers and flooding over the central United States. Journal of Climate, 26(20), 7829-7836.

Leathers, D. J., Yarnal, B., and Palecki, M. A. (1991). The Pacific/North American teleconnection pattern and United States climate. Part I: Regional temperature and precipitation associations. Journal of Climate, 4(5), 517-528.

Lins, H. F. and Cohn, T. A. (2011), Stationarity: Wanted Dead or Alive?. JAWRA Journal of the American Water Resources Association, 47, 475-480. doi: 10.1111/j.17521688.2011.00542.x

Lins, H. F. and Slack, J. R. (1999). Streamflow trends in the United States. Geophysical research letters, 26(2), 227-230.

Mallakpour, I., and Villarini, G. (2015).The changing nature of flooding across the central United States. Nature Climate Change, 5(3), 250-254.

Mantua, N. J., and Hare, S. R. (2002). The Pacific decadal oscillation. Journal of oceanography, 58(1), 35-44.

Mantua, N. J., Hare, S. R., Zhang, Y., Wallace, J. M., \& Francis, R. C. (1997). A Pacific interdecadal climate oscillation with impacts on salmon production. Bulletin of the american Meteorological Society, 78(6), 1069-1079 
McCabe, G. J., and Wolock, D. M. (2014). Spatial and temporal patterns in conterminous United States streamflow characteristics. Geophysical Research Letters, 41(19), 6889-6897.

McCabe, G. J., Palecki, M. A., and Betancourt, J. L. (2004). Pacific and Atlantic Ocean influences on multidecadal drought frequency in the United States. Proceedings of the National Academy of Sciences, 101(12), 4136-4141.

National Climate Data Center (NCDC),(2015) Billion-Dollar Weather and Climate Disasters, Retrieved July, 2015, from http://www.ncdc.noaa.gov/billions/events

National Oceanic and Atmospheric Administration (NOAA). (2015). Retrieved from NOAA's National Climatic Data Center http://www.ncdc.noaa.gov/teleconnections/enso/indicators/soi/

Nayak, M. A., Villarini, G., and Bradley, A. A. (2016). Atmospheric Rivers and Rainfall during NASA’s Iowa Flood Studies (IFloodS) Campaign. Journal of Hydrometeorology, 17(1), 257271.

Neiman, P. J., Ralph, F. M., Wick, G. A., Lundquist, J. D., and Dettinger, M. D. (2008). Meteorological characteristics and overland precipitation impacts of atmospheric rivers affecting the West Coast of North America based on eight years of SSM/I satellite observations. Journal of Hydrometeorology, 9(1), 22-47.

Nigam, S., Barlow, M., and Berbery, E. H. (1999). Analysis links Pacific decadal variability to drought and streamflow in United States. EOS, Transactions American Geophysical Union, 80(51), 621-625.

NING, L., and BRADLEY, R. S. (2014). Winter climate extremes over the northeastern United States and southeastern Canada and teleconnections with large-scale modes of climate variability. Journal of Climate, 28, 2475-2493.

Patricola, C. M., Chang, P., and Saravanan, R. (2015). Impact of Atlantic SST and high frequency atmospheric variability on the 1993 and 2008 Midwest floods: Regional climate model simulations of extreme climate events. Climatic Change, 129(3-4), 397-411.

Portis, D. H., Walsh, J. E., El Hamly, M., and Lamb, P. J. (2001). Seasonality of the North Atlantic oscillation. Journal of Climate, 14(9), 2069-2078.

R Core Team (2012). R: A language and environment for statistical computing. R Foundation for Statistical Computing, Vienna, Austria. ISBN 3-900051-07-0, URL http://www.Rproject.org/.

Risko, S. L., and Martinez, C. J. (2014). Forecasts of seasonal streamflow in West-Central Florida using multiple climate predictors. Journal of Hydrology, 519, 1130-1140.

Ropelewski, C.F., and P.D. Jones (1987). An Extension of the Tahiti-Darwin Southern Oscillation Index, Monthly Weather Review, 115:2161-2165

Sagarika, S., Kalra, A., and Ahmad, S. (2015). Interconnections between oceanic-atmospheric indices and variability in the US streamflow. Journal of Hydrology, 525, 724-736. 
Sankarasubramanian, A., and Lall, U. (2003). Flood quantiles in a changing climate: Seasonal forecasts and causal relations. Water Resources Research, 39(5).

Schilling, K. E., and R. D. Libra (2003), Increased baseflow in Iowa over the second half of the 20th century, Journal of the American Water Resources Association, vol. 39, 851- 860.

Sheridan, S. C. (2003). North American weather-type frequency and teleconnection indices. International Journal of Climatology 23(1), 27-45.

Slater, L. J., Singer, M. B., and Kirchner, J. W. (2015). Hydrologic versus geomorphic drivers of trends in flood hazard. Geophysical Research Letters, 42(2), 370-376.

Smith J.A., Karr, A. F., (1986). Flood frequency analysis using the Cox regression model. Water Resources Research, 22(6), 890-896.

Smith, J. A., Baeck, M. L., Villarini, G., Wright, D. B., and Krajewski, W. (2013). Extreme flood response: The June 2008 flooding in Iowa. Journal of Hydrometeorology, 14(6), 1810-1825.

Stenseth, N. C., Ottersen, G., Hurrell, J. W., Mysterud, A., Lima, M., Chan, K. S., Yoccoz, N., G. and Ådlandsvik, B. (2003). Studying climate effects on ecology through the use of climate indices: the North Atlantic Oscillation, El Nino Southern Oscillation and beyond. Proceedings of the Royal Society of London B: Biological Sciences, 270(1529), 2087-2096.

Tootle, G. A., and Piechota, T. C. (2006). Relationships between Pacific and Atlantic Ocean Sea surface temperatures and US streamflow variability. Water Resources Research, 42(7). DOI: 10.1029/2005WR004184.

Tootle, G. A., Piechota T. C., and Singh A (2005). Coupled oceanic-atmospheric variability and US streamflow. Water Resources Research, 41(12), DOI: 10.1029/2005WR004381.

Trenberth (1984), Signal versus Noise in the Southern Oscillation, Monthly Weather Review 112:326-332

Villarini, G. (2016). On the seasonality of flooding across the continental United States. Advances in Water Resources, 87, 80-91.

Villarini, G., Smith, J. A., Baeck, M. L., Vitolo, R., Stephenson, D. B., and Krajewski, W. F. (2011a). On the frequency of heavy rainfall for the Midwest of the United States. Journal of Hydrology, 400(1), 103-120.

Villarini, G., Smith, J. A., Baeck, M. L. and Krajewski,W (2011b). F. Examining flood frequency distributions in the Midwest US. J. Am.Water Resour. Assoc. 47, 4470-463.

Villarini, G., Smith, J. A., and Vecchi, G. A. (2013a). Changing frequency of heavy rainfall over the central United States. Journal of Climate, 26(1), 351-357.

Villarini, G., Smith, J. A., Vitolo, R., and Stephenson, D. B. (2013b). On the temporal clustering of US floods and its relationship to climate teleconnection patterns. International Journal of Climatology, 33(3), 629-640. 
Wang, H., Sankarasubramanian A., and Ranjithan, R. S. (2015).Understanding the lowfrequency variability in hydroclimatic attributes over the southeastern US. Journal of Hydrology, 521, 170-181.

Weaver, S. J., and Nigam, S. (2008). Variability of the Great Plains Low-Level Jet: Large-Scale Circulation Context and Hydroclimate Impacts. Journal of Climate, 21(7), 1532. 

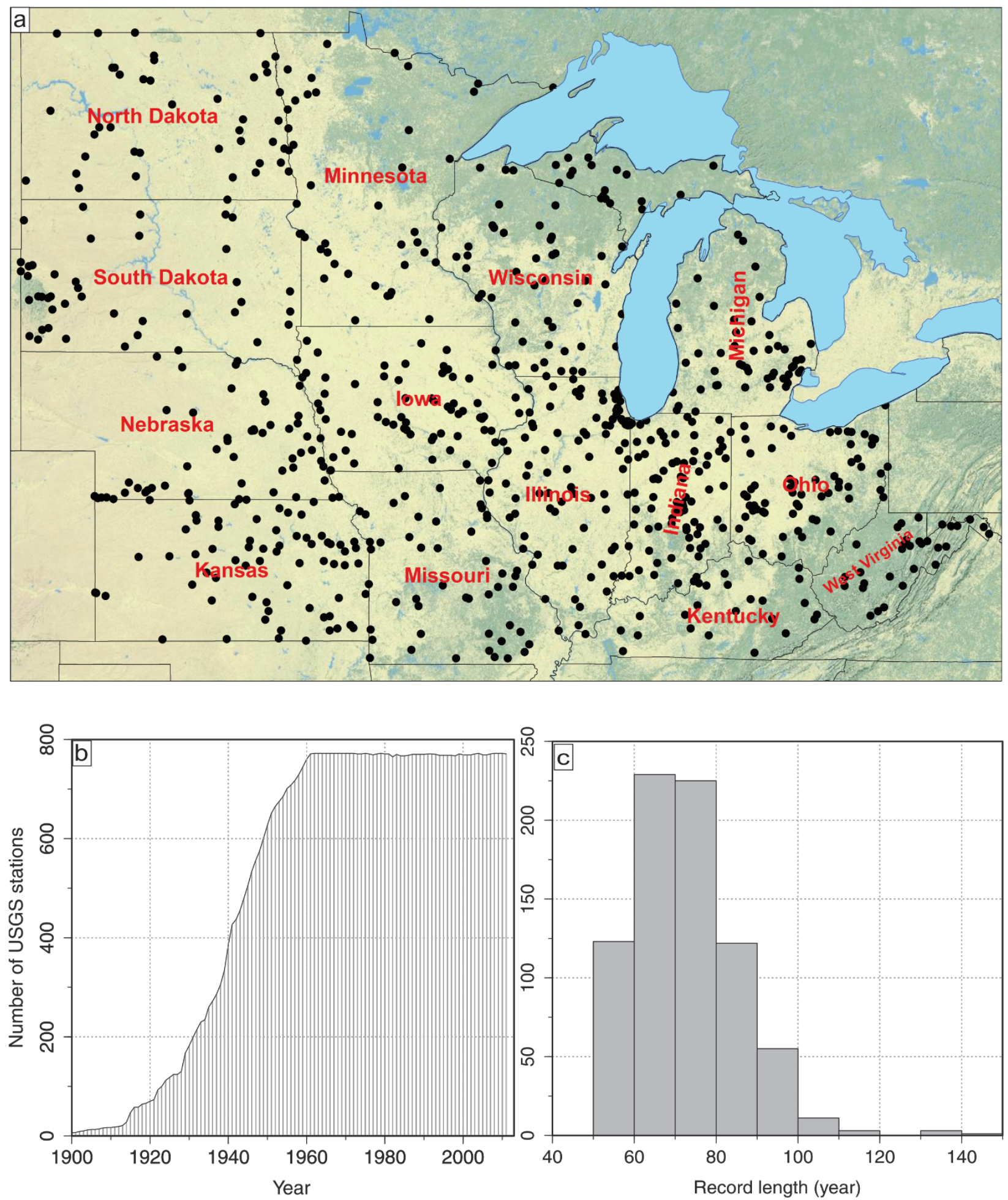

Figure 1. (a) Map showing the study area and the location of the 774 U.S. Geological Survey (USGS) stations (black circles) used in this study. (b) Number of available stations in a given year. (c) Histogram showing the length of record (in years) for all the stations used in this study. 


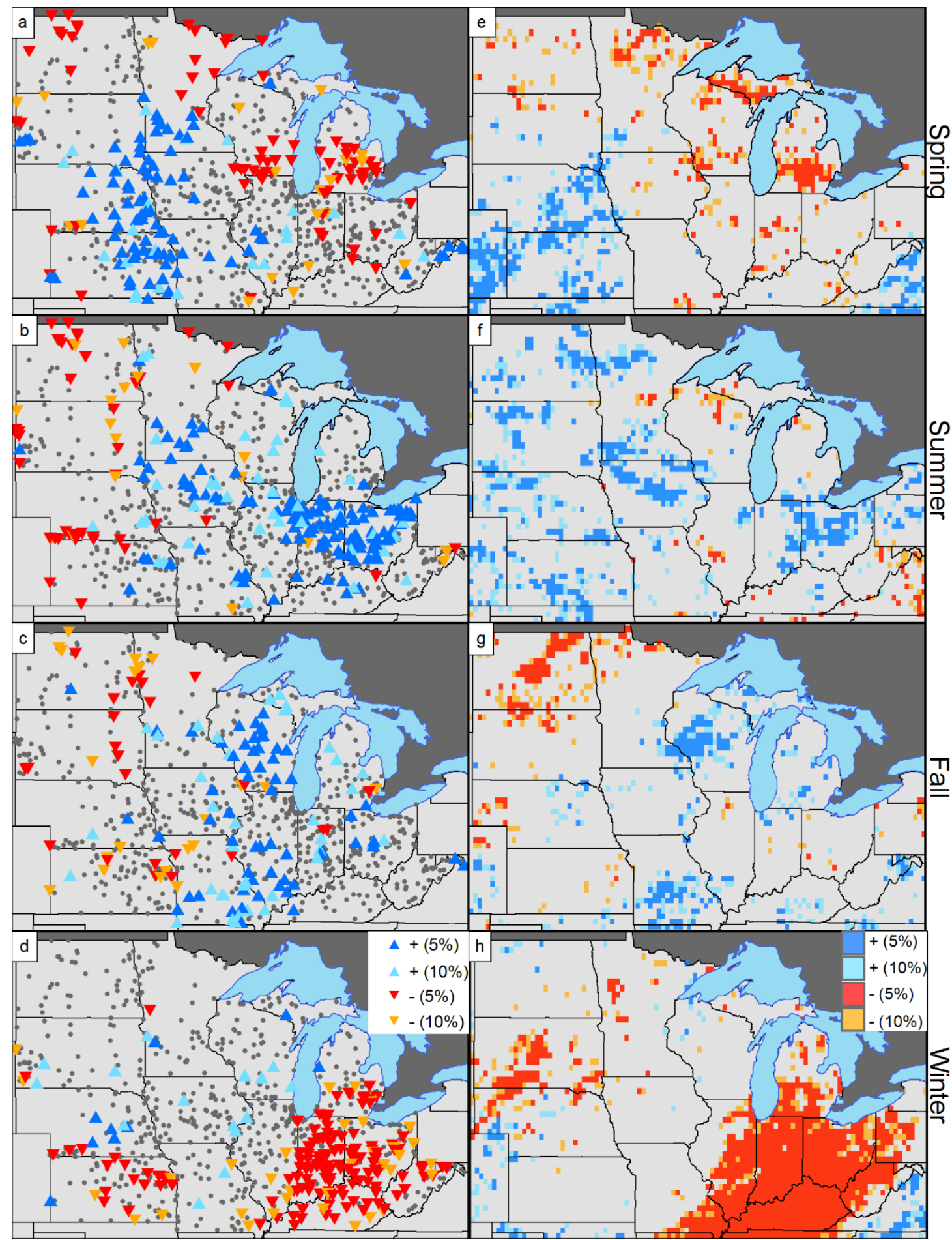

Figure 2. Maps summarizing the results for relationship between PDO and (a-d) the frequency of flooding and (e-h) the frequency of heavy precipitation events. The red (orange) colors indicate a statistically significant negative relationship at the 5\% (10\%) level; the dark (light) blue colors 
show a statistically significant positive relationship at the $5 \%(10 \%)$ level. The grey circles refer to locations that did not show a statistically significant relationship significant at the $10 \%$ level. 


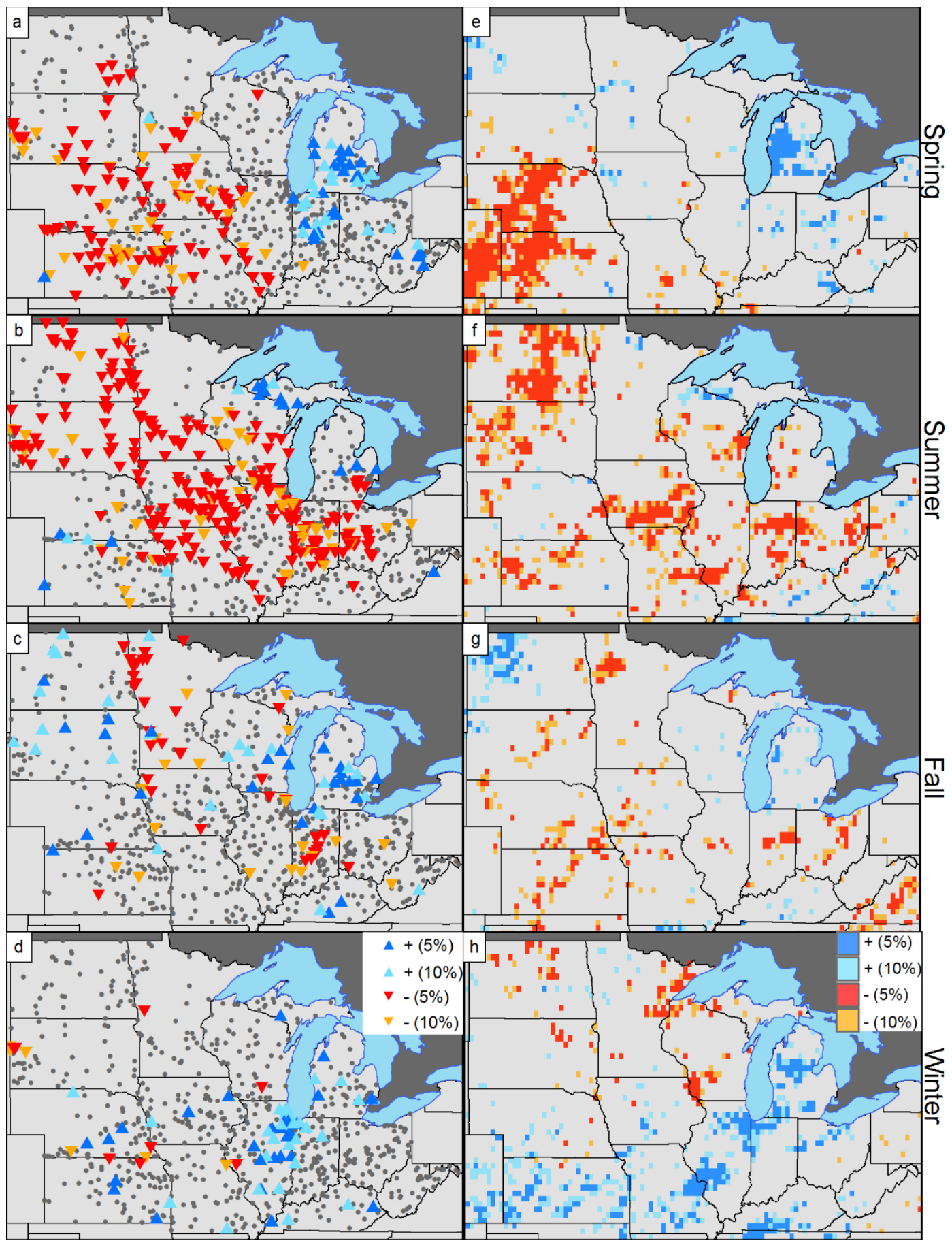

Figure 3. Same as Figure 2 but for the NAO index. 


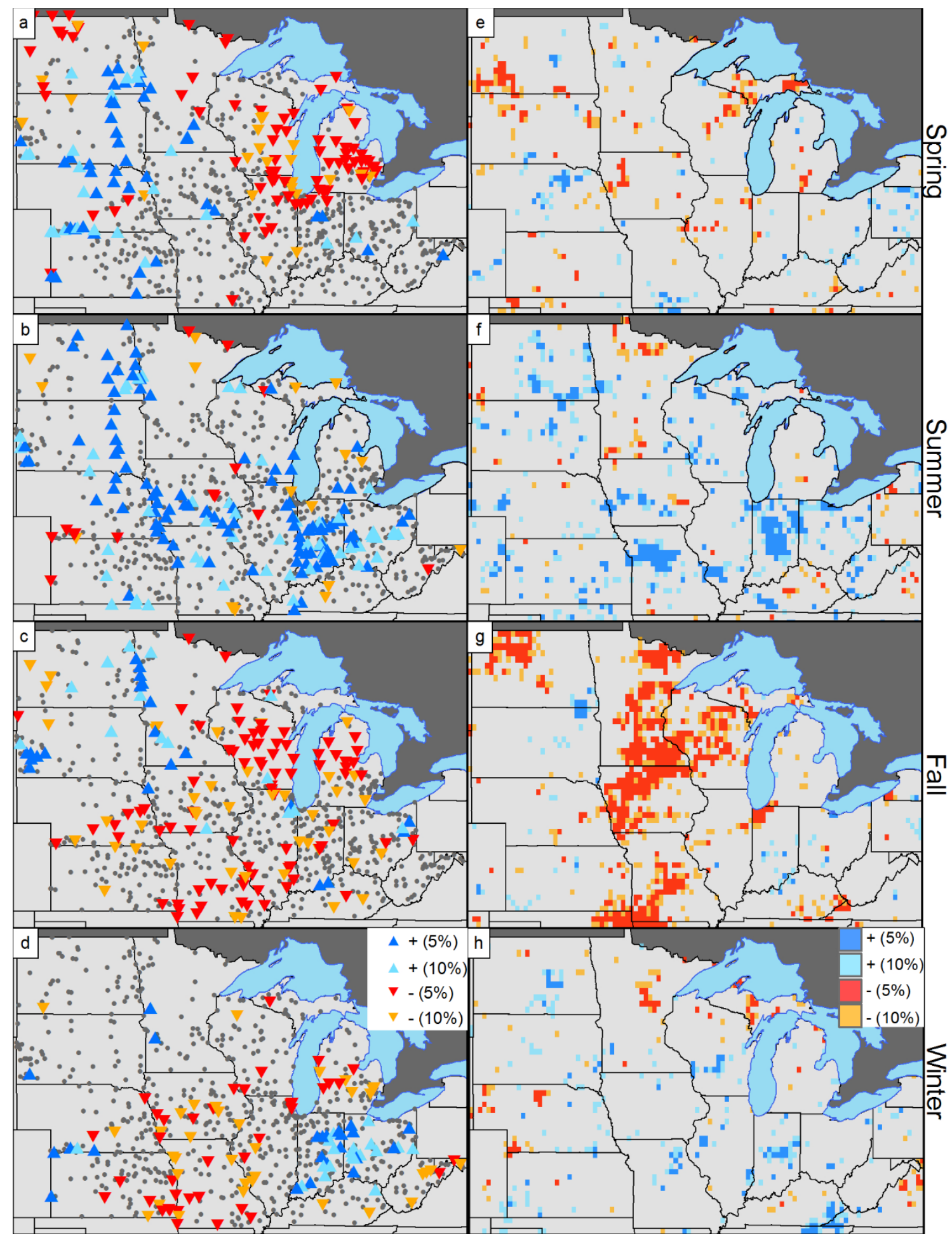

Figure 4. Same as Figure 2 but for the AMO index. 


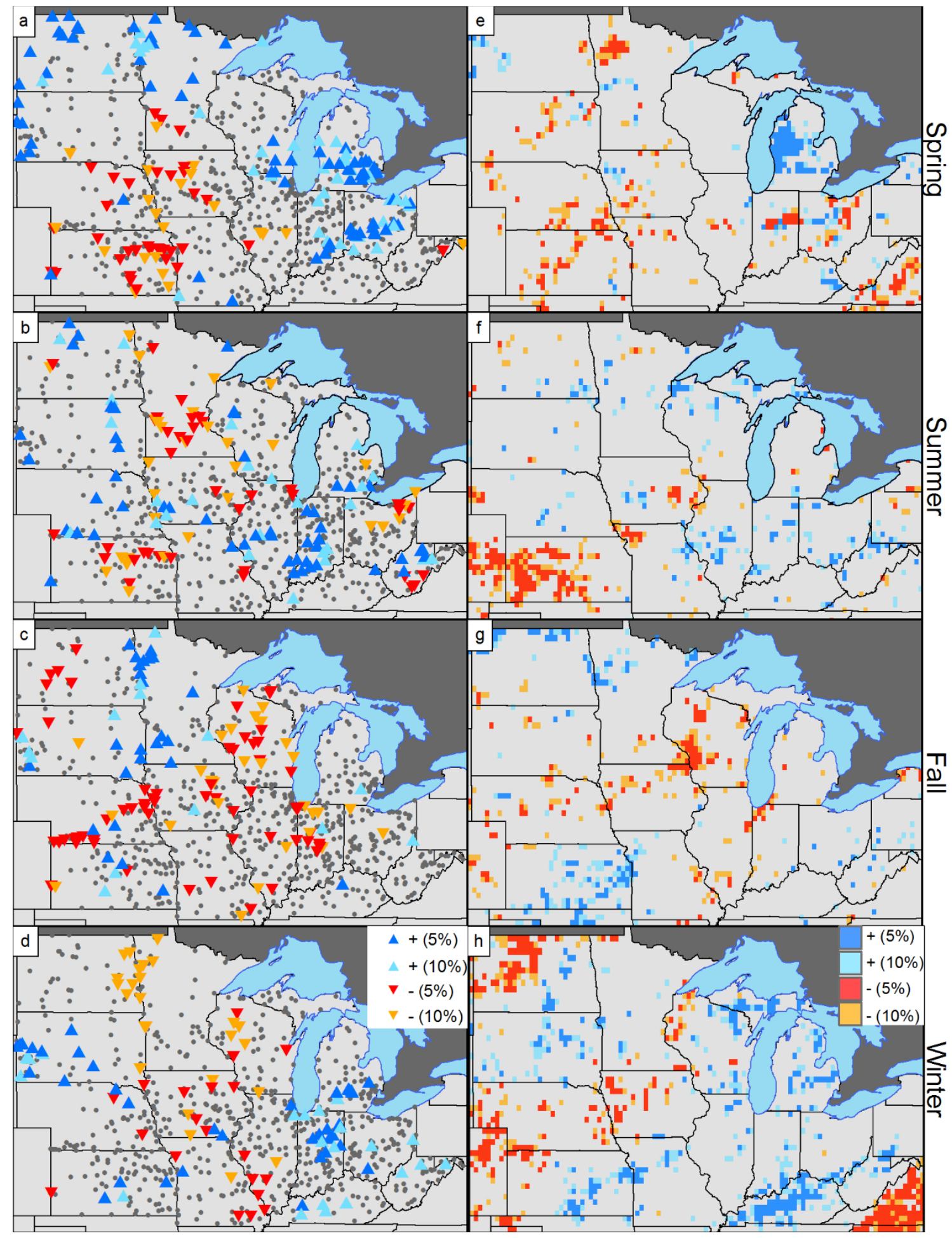

Figure 5. Same as Figure 2 but for the SOI index. 


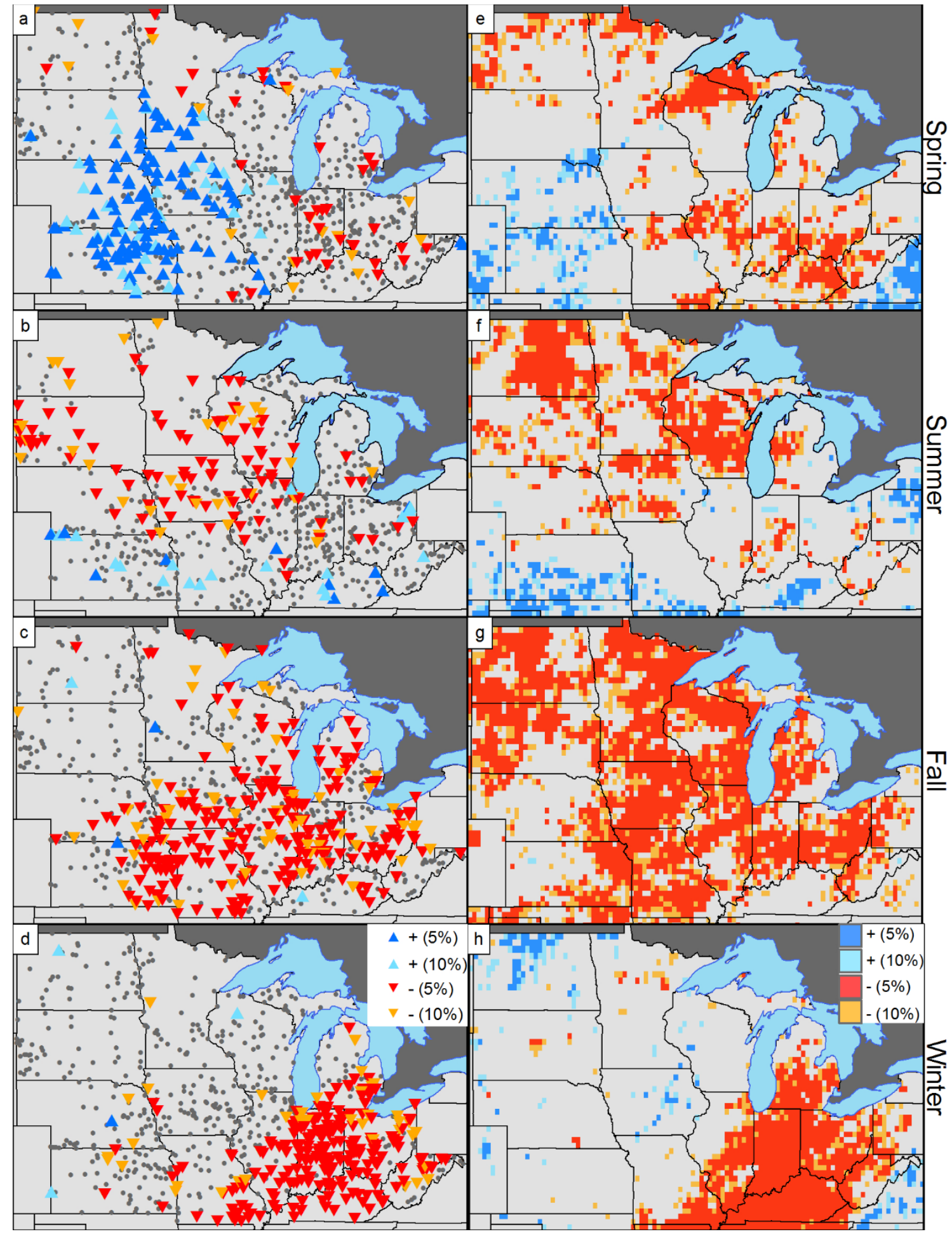

Figure 6. Same as Figure 2 but for the PNA index. 


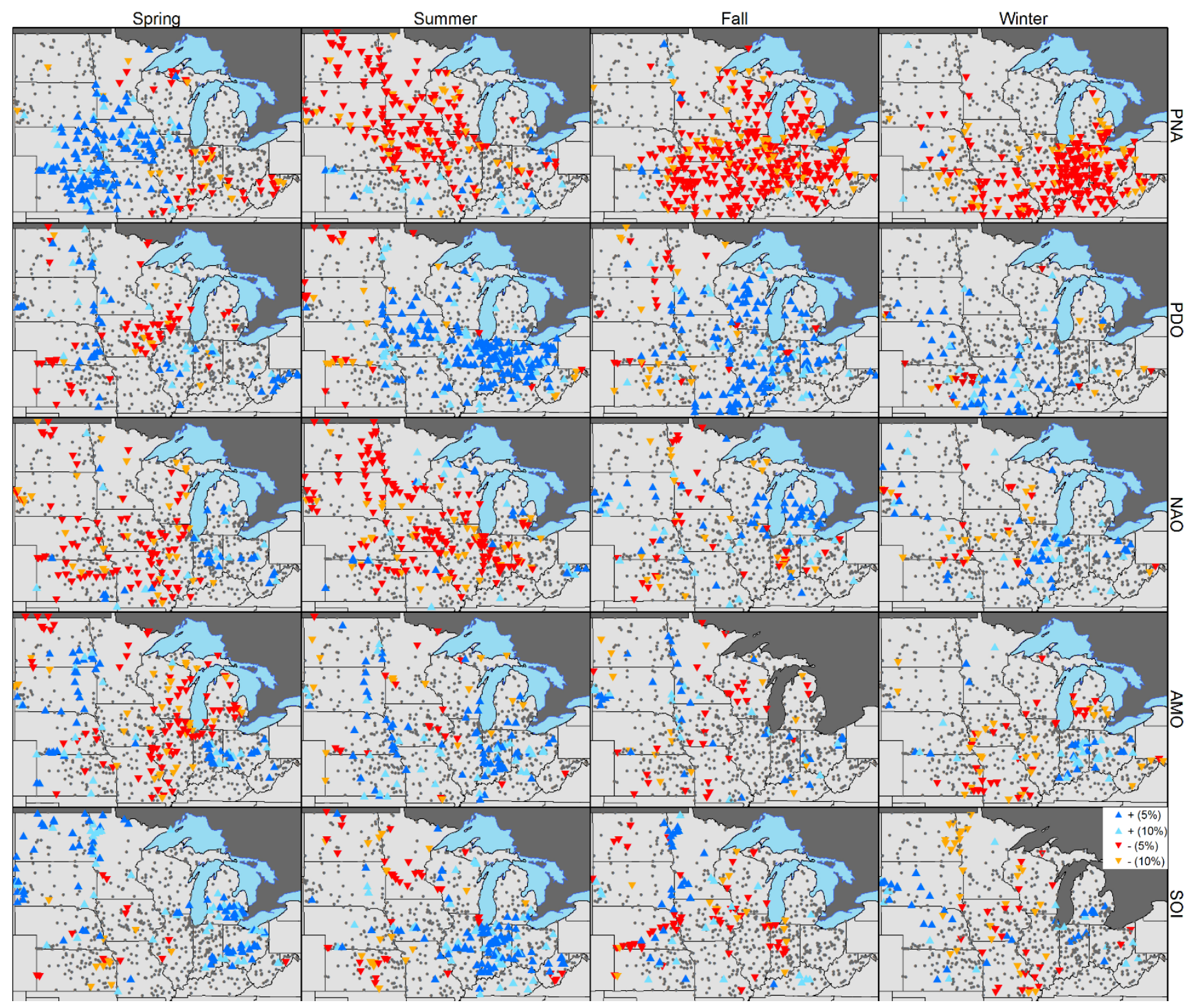

Figure 7. Maps showing the results of the multiple Poisson regression for the frequency of flood events. The red (orange) colors indicate a statistically significant negative relationship at the 5\% (10\%) level. The dark (light) blue colors show a statistically significant positive relationship at the $5 \%(10 \%)$ level. The grey circles refer to the location of the stations that did not show a statistically significant relationship at the $10 \%$ significant level. 


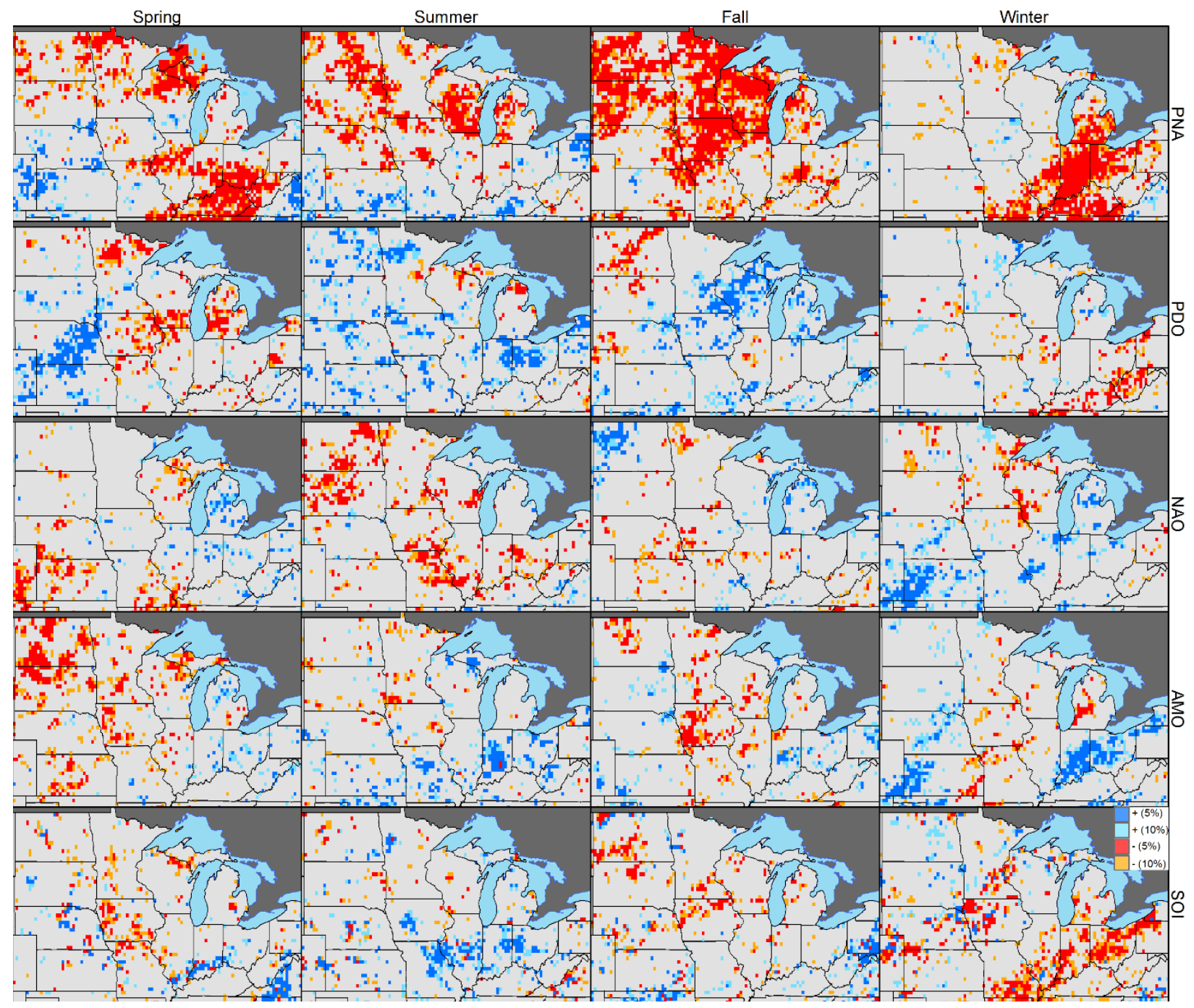

Figure 8. Same as Figure 7 but for the frequency of heavy precipitation events. 


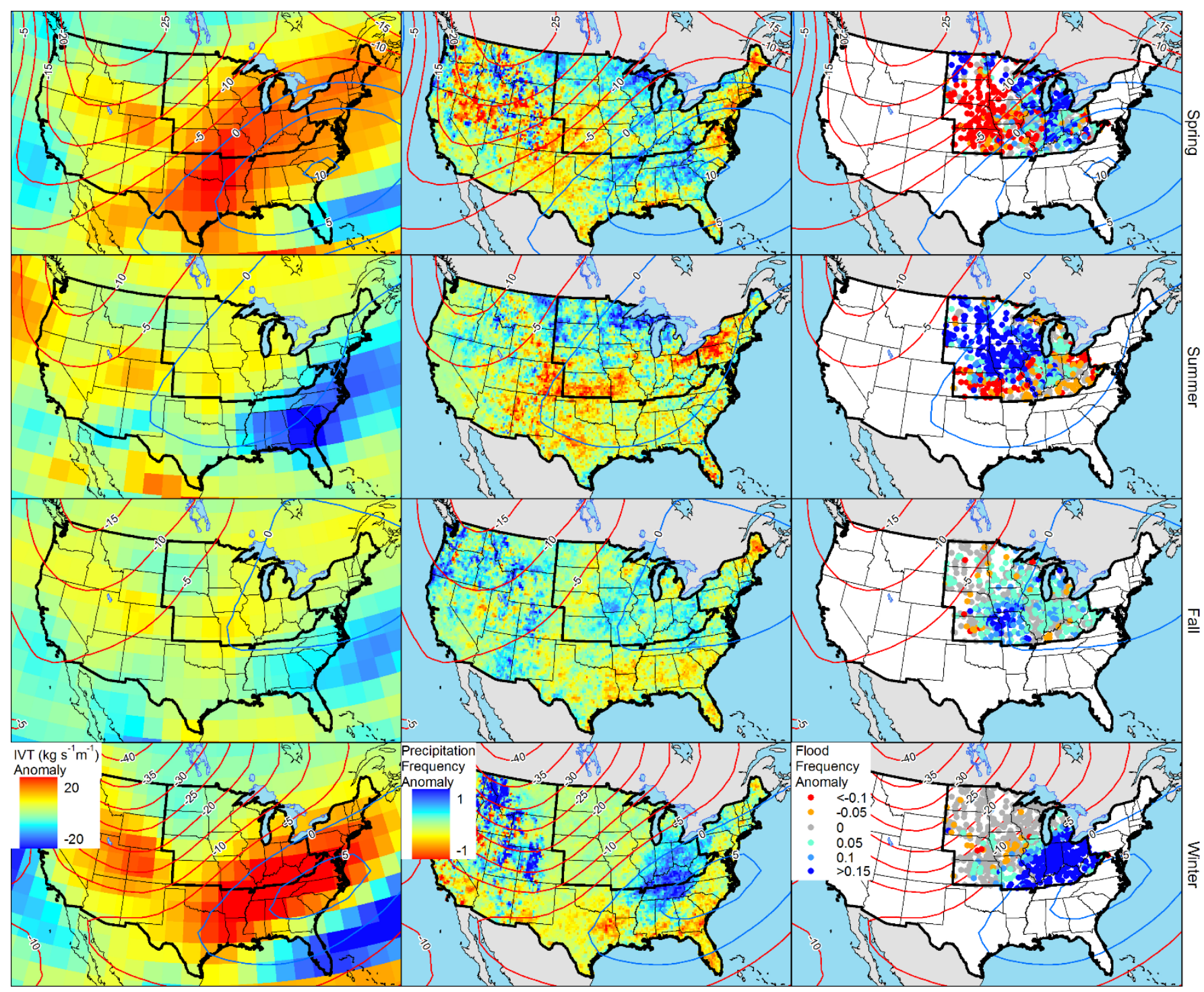

Figure 9. Maps showing the IVT anomaly (left column), heavy precipitation frequency anomaly (middle column) and flood frequency anomaly (right column) during the negative phase of PNA. In all these maps, the blue (red) contours represent positive (negative) 500-mb GPH anomalies (m). Anomalies are calculated for each season with respect to the 1980-2010 base period. 
Table 1: Summary of the fraction of stream gage stations with a statistically significant $(10 \%$ level) relationship with each of the climate indices based on the multiple Poisson regression.

\begin{tabular}{|c|c|c|c|c|c|c|c|c|}
\hline & \multicolumn{2}{|c|}{ Spring } & \multicolumn{2}{c|}{ Summer } & \multicolumn{2}{c|}{ Fall } & \multicolumn{2}{c|}{ Winter } \\
\hline & Positive & Negative & Positive & Negative & Positive & Negative & Positive & Negative \\
\hline PNA & 0.19 & 0.07 & 0.05 & 0.27 & 0.01 & 0.45 & 0.01 & 0.36 \\
\hline PDO & 0.08 & 0.08 & 0.28 & 0.05 & 0.21 & 0.05 & 0.08 & 0.03 \\
\hline NAO & 0.05 & 0.16 & 0.04 & 0.25 & 0.09 & 0.07 & 0.08 & 0.04 \\
\hline AMO & 0.09 & 0.15 & 0.13 & 0.05 & 0.05 & 0.07 & 0.05 & 0.08 \\
\hline SOI & 0.16 & 0.02 & 0.16 & 0.07 & 0.06 & 0.10 & 0.06 & 0.07 \\
\hline
\end{tabular}

